\title{
Association of Female Sexual Dysfunction and Fertility: a cross sectional study
}

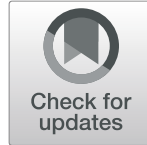

Felix Mwembi Oindi ${ }^{*}$ (D, Alfred Murage, Valentino Manase Lema and Abraham Mwaniki Mukaindo

\begin{abstract}
Background: Sexual function plays an essential role in the bio-psychosocial wellbeing and quality of life of women and disturbances in sexual functioning often result in significant distress. Female sexual dysfunction (FSD) and subfertility are common problems affecting approximately 43 and $20 \%$ of women respectively. However, despite the high prevalence of both conditions, little has been studied on the effects of subfertility on sexual functioning especially in sub-Saharan Africa. We set out to compare the prevalence of female sexual dysfunction in patients on assessment for sub-fertility and those either seeking or already on fertility control services at a private tertiary teaching hospital in Kenya.

Methods: This was an analytical cross sectional study. Eligible women of reproductive age (18-49 years), attending the gynaecological clinics with complaints of subfertility and those seeking fertility control services were requested to fill a general demographic tool containing personal data and the Female Sexual Function Index (FSFI) questionnaire after informed consent. Prevalence of sexual dysfunction was calculated as a percentage of patients not achieving an overall FSFI score of 26.55. Univariate and multivariate analysis were done to compare clinical variables to delineate the potential association.

Results: The prevalence of female sexual dysfunction was $31.2 \%$ in the subfertile group and $22.6 \%$ in fertility control group. The difference was not statistically significant $(p=0.187)$. The mean domain and overall female sexual function scores were lower in the subfertile group than the fertility control group though this was not statistically significant. The most prevalent sexual domain dysfunctions in both the subfertility and fertility control groups were desire and arousal while the least in both groups was satisfaction dysfunction. Subfertility type was not associated with sexual dysfunction. Higher education attainment was protective of female sexual dysfunction in the subfertile group while use of hormonal contraception was associated with greater sexual impairment in the fertility control group. On logistic regression analysis, higher maternal age and alcohol use appeared to be protective against sexual dysfunction.

Conclusion: The present study demonstrated no association between the fertility status and the prevalence female sexual dysfunction. Subfertility type was not associated with sexual dysfunction. Education level and hormonal contraception use were associated with female sexual dysfunction in the subfertile and fertility control groups respectively while alcohol use and higher maternal age appeared to be protective against sexual dysfunction.
\end{abstract}

Keywords: Female sexual dysfunction, Subfertility, Female sexual function index, Questionnaire.

\footnotetext{
* Correspondence: droindi@gmail.com

Department of Obstetrics and Gynaecology, Aga Khan University Hospital,

Nairobi, Kenya
}

(c) The Author(s). 2019 Open Access This article is distributed under the terms of the Creative Commons Attribution 4.0 International License (http://creativecommons.org/licenses/by/4.0/), which permits unrestricted use, distribution, and reproduction in any medium, provided you give appropriate credit to the original author(s) and the source, provide a link to the Creative Commons license, and indicate if changes were made. The Creative Commons Public Domain Dedication waiver (http://creativecommons.org/publicdomain/zero/1.0/) applies to the data made available in this article, unless otherwise stated. 


\section{Plain language summary}

Female sexual dysfunction is a common condition affecting approximately $43 \%$ of women. Subfertility is also common affecting approximately 1 in 5 couples. This study aimed to compare sexual function between patients on fertility assessment and those seeking family planning services. A questionnaire (Female sexual function index questionnaire) was used to the collect the patients' data and sexual history which was then analyzed.

Of the 186 respondents (93 in the subfertility group and 93 in the family planning group), 50 had impaired sexual function. Of these, 29 were from the subfertility group while 21 were from the family planning group. The most affected sexual function domains in both groups were desire and arousal while the least affected was satisfaction.

In the fertility control group, women with higher education attainment had less sexual dysfunction while in the family planning group, women on hormonal contraception had more sexual dysfunction. Women who used alcohol and those above 35 years of age had a lesser sexual dysfunction.

In conclusion, being subfertile was not associated with female sexual dysfunction. Maternal age, education level, use of alcohol and use of hormonal contraception affected sexual function and need to be explored further.

\section{Background}

Sexual function plays a central role in the biopsychosocial wellbeing and quality of life of human beings [1]. It encompasses issues such as sex, reproduction, pleasure, intimacy, erotism, identity and gender roles, and sexual orientation [2] and is under the dynamic interaction of the physical, economic, religious, psychological and emotional factors [2, 3]. Any impairment in sexual function could have detrimental effects on the quality of life of the affected subjects [4].

Female Sexual Dysfunction (FSD) is defined as a "disorder of sexual desire, arousal, orgasm, and sexual pain that results in significant personal distress. It is a multifactorial, age-related and progressive problem" $[5,6]$ that is based on disturbances to the female sexual response.

Female sexual dysfunction affects approximately $43 \%$ of women according to data from the National Health and Social Survey (1992; $n=1749 ; 18-59$ years old women) [7]. It is more prevalent in women with chronic ailments, genital atrophy, history of sexual abuse and those with psychosocial stressors such as subfertility and poor interpersonal relationships [8]. In particular, women with subfertility have been shown to have up to one and half times greater prevalence of sexual dysfunction than their fertile counterparts $[9,10]$.

Subfertility is an "emotional rollercoaster" to affected couples more so women with resultant mental stress [11].
It is a significant life stressor and might negatively impact on sexual function. The psychological stress of subfertility which would stem from the societal perception of the sub-fertile 'woman' who may be considered to be undergoing a punishment from a previous behavior like premarital sex or abortion, or from the physical pressure to conceive may result in new or aggravation of existing sexual dysfunction. The subfertile couple is more prone to depression, anxiety and stress [12, 13]. The increased stress levels would adversely affect the marital satisfaction and adversely affect their sexual health. On the other hand, the medical procedures for investigation or treatment of subfertility may arouse a sense of anxiety and hence affect sexual functioning [12].

Whether sexual dysfunction is the cause or consequence of subfertility is difficult to establish. For instance, sexual dysfunction might result in decreased coital frequency compounding the issue of subfertility due to reduced exposure. On the other hand, the psychological pressure to get pregnant stemming from sex on demand could result in a reduction in enjoyment of sex aggravating sexual dysfunction. Indeed, situational sexual dysfunction and loss of a couple's intimacy may occur as a consequence of timed intercourse where focus for coitus is no longer pleasure but conception [10]. Therefore, the relationship between subfertility and sexual function might be bidirectional and need to be addressed for adequate management of either problem. Early diagnosis and treatment of sexual dysfunction among this group of patients might improve outcomes of subfertility treatment.

Data on sexual dysfunction in sub-Saharan Africa, especially Kenya is scarce. This was, to the best of our knowledge, the first study evaluating the prevalence of female sexual dysfunction among patients on follow up for subfertility in the region. As a result, we set out to compare sexual function among patients on subfertility assessment and those seeking fertility control services at a private tertiary teaching hospital in Kenya. The choice for fertility control clients was that they are presumably sexually active and having normal sexual functioning, hence seeking contraception to avoid a pregnancy. The study of female sexual dysfunction is particularly important in our society where the topic of sexuality is considered a taboo by many and many patients may not freely discuss such issues.

\section{Methodology \\ Objective}

To compare the prevalence of sexual dysfunction, as measured by the FSFI-Q, between patients on assessment for subfertility and those either seeking or on various contraceptive methods at the Aga Khan University Hospital, Nairobi. 


\section{Study design}

This was an analytic cross sectional study.

\section{Study setting and participants}

The study was conducted at the Aga Khan University Hospital Gynaecology outpatient Clinics which run on every weekday. Both new and old patients on various stages of fertility assessment or treatment and those presenting for or already on a contraceptive method were approached and assessed for eligibility. Eligible participants who provided informed consent were recruited. A sub-fertile patient was defined as one with inability to conceive after at least 12 months of regular unprotected coitus [12]. The eligibility criteria was as follows:

\section{Inclusion criteria was}

Women 18-49 years of age attending the gynaecology outpatient clinic with subfertility and those either seeking or already on a family planning method who were sexually active in the preceding 4 weeks and had English literacy as the questionnaire was self-administered in English and due to unavailability of a validated form of the FSFI-Q in the Kiswahili language commonly spoken in Kenya.

\section{Exclusion criteria was}

Pregnant patients and those in the puerperium; those with gynaecologic conditions like malignancies, fistula, chronic pelvic pain, genital prolapse and lower genital tract abnormality; those with medical conditions associated with sexual dysfunction like diabetes, hypertension, endocrine disorders and psychiatric illnesses and those who previously had pelvic floor surgery were excluded due potential effect of these conditions on sexual function.

\section{Study procedures and tools}

Patients attending the gynaecology clinic with subfertility and those presenting for or already on contraception were approached by the principal investigator or the research assistants for eligibility. Eligible participants were then requested to fill the two data collection tools, the FSFI-Q and the general demographic tool, after an explanation and giving informed consent. The demographics tool collected information on the age, parity (and previous pregnancy outcomes), BMI and other associated factors that might impact on sexual function. Some of these included the partner's age, educational level, marital status, contraceptive use (and type), alcohol and substance use and abuse, history of sexual abuse, and social support. These tools were selfadministered and the participants were recruited by convenience sampling. Sexual function was measured using the domains in the FSFI-Q with those with overall scores below 26.55 being considered to have impaired sexual functioning [2]. The participants who wished to know their FSFI scores were informed by phone and those with scores below 26.55 were advised to attend the sexual health clinic for further assessment and management. None of the approached participants declined taking part in the study.

\section{Sample size calculation and sampling method}

The baseline prevalence level for sexual dysfunction in the general population was assumed to be $43 \%$ based on a prior study [7]. It is estimated that subfertile patients experience up to $50 \%$ greater sexual dysfunction (i.e. $64.5 \%)$ than their general counterparts $[9,10]$. Sexual function in women on various fertility control services is not statistically different from that of the general population [14-16] hence women seeking fertility control were used as a control group. There being no local data on female sexual dysfunction in the general population let alone in subfertile patients, we assumed the prevalence as reported in literature and utilized it in the calculation of the sample size. Sample size calculation was done using the formula for comparing two proportions:

$n=\left(\mathrm{Z}_{\alpha / 2}+\mathrm{Z}_{\beta}\right)^{2 *}\left(\mathrm{p}_{1}\left(1-\mathrm{p}_{1}\right)+\mathrm{p}_{2}\left(1-\mathrm{p}_{2}\right)\right) /\left(\mathrm{p}_{1}-\mathrm{p}_{2}\right)^{2}$.

Where:

$n=$ required sample size per group.

$\mathrm{Z}_{\alpha / 2}=$ the critical value of the Normal distribution at $\alpha / 2$ (For a confidence level of $95 \%$, $\alpha$ is 0.05 and the critical value is 1.96).

$Z_{\beta}=$ the critical value of the Normal distribution at $\beta$ (For a power of $80 \%, \beta$ is 0.2 and the critical value is 0.84 ).

$\mathrm{P}_{1}$ and $\mathrm{P}_{2}=$ the expected sample proportions of the two groups.

$\mathrm{P}_{1}=0.43 \mathrm{P}_{2}=0.43+0.5(0.43)=0.645$.

Therefore:

$n=(1.96+0.84)^{2 * *}(0.645(1-0.645)+0.43(1-0.43) /$

$(0.645-0.43)^{2}$.

$n=93$.

Total sample size $=n * 2=93 * 2=186$.

\section{Data management and analysis}

The prevalence of sexual dysfunction was determined as the percentage of patients with domain and overall scores below the cut-off levels. Chi-square test was used to test the association between the categorical variables. The patients' socio-demographics characteristics were compared to determine any association between the patients with sexual dysfunction and those without sexual dysfunction. Univariate analysis was done to evaluate the relationship of each socio-demographic characteristic with sexual dysfunction in the sub-fertile group. The same was done for the subjects seeking or on fertility control services in order to delineate the potential pattern of association. Univariate logistic regression analysis 
were conducted for variables with potential confounding effect on sexual dysfunction. Logistic regression models were constructed after which logistic regression was performed for an adjusted odds ratio for each of the factors. Data values were expressed as mean \pm SD, count (\%) and odds ratio. $P<0.05$ was considered statistically significant. Data analysis was performed using STATA version 12.0 and the data expressed in tables and graphs.

\section{Ethical considerations}

Ethical approval was sought from the Aga Khan University Ethics Committee before commencing the study. Prior to being involved in the study, the participants gave a written informed consent. Patients were informed that they had a right to refuse or withdraw from the study at any point and this would not impact on the quality of care received subsequently. Patient confidentiality and privacy was maintained during the entire study period with use of number identifiers alongside safe and restricted data storage. The data collection forms were safely kept in a locked cabinet to which only the primary investigator and the research assistants had access to. Subjects with sexual dysfunction were referred to the sexual health clinic for further evaluation and management. None of the study participants aged below 18 years.

\section{The female sexual function index questionnaire (FSFI-Q)}

The FSFI-Q is a multidimensional self-report tool for assessing key dimensions of female sexual functioning over the preceding 4 weeks $[17,18]$. This standardized questionnaire described by Rosen and colleagues [17] consists of 19-items that assess six domains of female sexual functioning. The domains include: sexual desire (items 1 and 2), arousal (items 3-6), lubrication (items 7-10), orgasm (items 11-13), satisfaction (items 14-16) and sexual pain (items 17-19). Each of the items has a Likert scale score ranging from 0 to 5 and each of the 6 domains' scores are calculated by adding the scores of the individual items that comprise the domain and multiplying by a respective domain factor which homogenizes each dimension's influence. The full scale or total FSFI score ranges from 2 to 36 and is the sum of all the scores in the six domains [2, 4]. Higher scores indicate a better sexual functioning with a 26.55 or less cut off score indicative of sexual dysfunction according to a validation study [2]. Equally, each of the domains has a cutoff for sexual dysfunction.

\section{Results}

\section{Patient characteristics}

A total of 186 women were recruited by convenience sampling over the study duration (November 2015 to November 2016). Of these, 93 had presented with subfertility and were at various stages of fertility assessment while the other 93 had presented either for fertility control services or were already on a fertility control service. The mean age of the participants was 32.4 (SD 5.79 ) with the biggest group (58.6\%) being the 30-39 age group. Similarly, a great proportion of the partners were below 40 years (68.9\%). Majority of the women were married (81.7\%) and had a university education (90.3\%). The study participants were mostly non-obese (80.7\%) and majority reported not using alcohol (64.5\%). Only 4 patients $(2.2 \%), 2$ in the subfertility and 2 in the fertility control groups, reported a history of smoking while only $2(1.1 \%)$ reported a history of rape (both being in the subfertility group). However, 6 patients (3.2\%) had missing data on the history of rape. Three of these were from the subfertility group while 3 were from the fertility control group.

The subfertile and fertility control subjects did not differ significantly in terms of body mass index (BMI), previous miscarriage, education level, frequency of coitus and history of alcohol use. We would not adequately compare those with a smoking history or rape. The two groups however exhibited significant differences in their ages, partner's age, marital status and previous live birth (Table 1). The subfertile subjects and their partners were more likely to be older and married but less likely to have had a previous live birth when compared to the fertility control subjects.

\section{Female sexual dysfunction prevalence as per female sexual function index questionnaire (FSFI-Q)}

Using a cutoff score of 26.55 on the FSFI-Q, the prevalence of female sexual dysfunction (FSD) was 26.9\% among the combined study subjects. On the other hand, the prevalence of FSD was $31.2 \%(n=29$ of 93$)$ and $22.6 \%$ ( $n=21$ of 93$)$ in the subfertile and fertility control groups respectively which was not statistically significant $(p=0.187)$. Moreover, despite the subfertile group portraying lower mean overall and domain scores, these were not statistically significant from the fertility control group (Table 2).

The most affected domains in both the subfertility and fertility control groups were desire and arousal while the least affected in both groups was the satisfaction domain. The proportion of those with sexual dysfunction in all the domains and total FSF score was higher in the subfertility group than the fertility control group though none was statistically significant (Fig. 1).

There were 40 women with primary subfertility and 53 with secondary subfertility. The prevalence of FSD in the primary and secondary subfertile women was $32.5 \%$ $(n=13)$ and $30.2 \%(n=16)$ respectively which was not significantly different $(p=0.057)$. 
Table 1 Socio-demographic characteristics of the subfertile and fertility control subjects

\begin{tabular}{|c|c|c|c|}
\hline Parameter & Subfertile group $(n=93)$ & Fertility control group $(n=93)$ & $P$-value \\
\hline \multicolumn{4}{|l|}{ Age (years) } \\
\hline $20-29(\%)$ & $18(19.35)$ & 37 (39.78) & \\
\hline $30-39(\%)$ & $56(60.22)$ & $53(56.99)$ & \\
\hline $40-49(\%)$ & $19(20.43)$ & $3(3.23)$ & \\
\hline Mean \pm SD & $34.20 \pm 5.72$ & $30.51 \pm 5.27$ & $<0.001^{\mathrm{a}}$ \\
\hline \multicolumn{4}{|l|}{ Body Mass Index $\left(\mathrm{Kg} / \mathrm{m}^{2}\right)$} \\
\hline Underweight $(<18)$ & $1(1.08)$ & $2(2.15)$ & \\
\hline Normal weight (18-24.9) & $32(34.41)$ & $35(37.63)$ & \\
\hline Overweight [19-24] & $42(45.16)$ & $38(40.86)$ & \\
\hline Obese (> 30) & 18 (19.35) & $18(19.35)$ & \\
\hline Mean \pm SD & $26.72 \pm 4.24$ & $26.14 \pm 4.35$ & $0.358^{\mathrm{a}}$ \\
\hline \multicolumn{4}{|l|}{ Partner Age (years) } \\
\hline$<40$ & $59(63.44)$ & $71(76.34)$ & \\
\hline$\geq 40$ & $34(36.56)$ & $22(23.66)$ & \\
\hline Mean \pm SD & $37.73 \pm 8.28$ & $34.14 \pm 5.72$ & $<0.001^{\mathrm{a}}$ \\
\hline Marital Status (married vs unmarried) & & & $<0.001^{b}$ \\
\hline Married & $89(95.70)$ & $63(67.74)$ & \\
\hline Married $\leq 3$ years & $25(26.88)$ & $23(36.51)$ & $0.385^{b}$ \\
\hline Married $>3$ years & $65(69.89)$ & $40(63.49)$ & \\
\hline Mean \pm SD & $6.79 \pm 4.66$ & $6.10 \pm 4.32$ & \\
\hline Single & $4(4.3)$ & $30(32.3)$ & \\
\hline Previous live birth & & & $<0.001^{b}$ \\
\hline Present & $33(35.48)$ & $60(64.52)$ & \\
\hline None & $60(64.52)$ & $33(35.48)$ & \\
\hline Previous miscarriage & & & $0.130^{b}$ \\
\hline Yes & $35(37.63)$ & $25(26.88)$ & \\
\hline None & $58(62.37)$ & $68(73.12)$ & \\
\hline Education Level & & & $0.621^{b}$ \\
\hline < 8years (Primary) & $3(3.23)$ & $1(1.08)$ & \\
\hline $8-12$ years (Secondary) & $6(6.45)$ & $7(7.53)$ & \\
\hline > 12 years (College) & $84(90.33)$ & $85(91.4)$ & \\
\hline Frequency of coitus & & & $0.760^{b}$ \\
\hline$\leq 10$ per month & $43(46.24)$ & $46(49.46)$ & \\
\hline$>10$ per month & $50(53.76)$ & $47(50.54)$ & \\
\hline History of alcohol use & & & $0.123^{b}$ \\
\hline Yes & $28(30.11)$ & $38(40.86)$ & \\
\hline None & $65(69.89)$ & 55 (59.14) & \\
\hline
\end{tabular}

${ }^{\mathrm{a}}$ Student's t-test; ${ }^{\mathrm{b}} \mathrm{Chi}$ square test

\section{Analysis of factors associated with female sexual dysfunction}

On evaluation of the association between the various socio-demographic variables and sexual dysfunction among the subfertility group, only education level was significantly associated with sexual dysfunction (Table 3). Women with college level education were less likely to have sexual dysfunction when compared to those with no college education. The duration of subfertility $(\leq 3$ years vs $>3$ years) did not appear to affect sexual function (OR 0.82, CI 0.34-1.96, $p=0.666$ ).

For the fertility control group, only the use of hormonal contraception was significantly associated with sexual dysfunction (Table 4). The duration of marriage 
Table 2 Mean domain-specific scores and overall sexual index (fsfi) questionnaire scores in women presenting with subfertility and for fertility control

\begin{tabular}{lllll}
\hline FSFI Domain & Subfertility $(n=93)$ & Fertility control $(n=93)$ & Maximum score & $P$-value \\
\hline Desire & $3.85 \pm 0.97$ & $3.97 \pm 0.92$ & 6.0 & $0.388^{\mathrm{a}}$ \\
Arousal & $4.37 \pm 1.03$ & $4.62 \pm 0.85$ & 6.0 & $0.073^{\mathrm{a}}$ \\
Lubrication & $5.03 \pm 0.99$ & $5.17 \pm 0.99$ & 6.0 & $0.336^{\mathrm{a}}$ \\
Orgasm & $4.69 \pm 1.27$ & $4.86 \pm 1.11$ & 6.0 & $0.332^{\mathrm{a}}$ \\
Satisfaction & $5.02 \pm 1.11$ & $5.32 \pm 0.87$ & 6.0 & $\mathbf{0 . 0 4 2 ^ { \mathrm { a } }}$ \\
Pain & $4.93 \pm 1.26$ & $5.12 \pm 1.01$ & 36.0 & $0.258^{\mathrm{a}}$ \\
Total Sexual function Score & $27.86 \pm 5.14$ & $29.14 \pm 3.82$ & & $0.056^{\mathrm{a}}$ \\
Number (\%) of women with FSFI score of $<26.55$ & $29(31.2 \%)$ & $21(22.6 \%)$ & & $0.187^{\mathrm{b}}$ \\
\hline
\end{tabular}

Data expressed as mean \pm SD

${ }^{\mathrm{a}}$ Student's t-test ${ }^{\mathrm{b}} \mathrm{Chi}$ square test

( $\leq 3$ years vs $>3$ years) among the married $(n=63$ $(67.7 \%))$ did not appear to be significantly associated with female sexual dysfunction (OR 1.42, CI 0.37-5.29, $p=0.602$ )

Stepwise regression modelling was employed to evaluate the association of the socio-demographic variables with FSD. The initial step assessed each of the variable's association with subfertility. Variables found to be significantly associated with subfertility were age (OR 2.10, CI 1.11-3.98, $p=0.020$ ), previous live birth (OR 0.30, CI $0.16-0.57, \mathrm{p}=<0.001$ ), marital status (OR 10.6, CI 3.27$34.29, \mathrm{p}=<0.001$ ) and partner's age (OR 2.04, CI 1.06$3.96, p=0.030)$

The variables were then assessed for their association with sexual dysfunction. The variables found to be significantly associated to sexual dysfunction were education level (OR 0.32, CI 0.12-0.88, $p=0.02$ ) and alcohol use (OR 0.42, CI 0.19-0.90, $p=0.021$ ). From the two steps, no variable emerged to be a potential confounder given that none was significantly associated with both subfertility and sexual dysfunction. Subfertility was not associated with sexual dysfunction (Crude OR 1.55, CI $0.80-3.00, p=0.187$ )

From the logistic regression, only alcohol use and higher maternal age affected sexual function with both appearing to be protective (Table 5)

\section{Discussion}

Sexual dysfunction is a common problem which can negatively affect a woman's self-esteem, quality of life

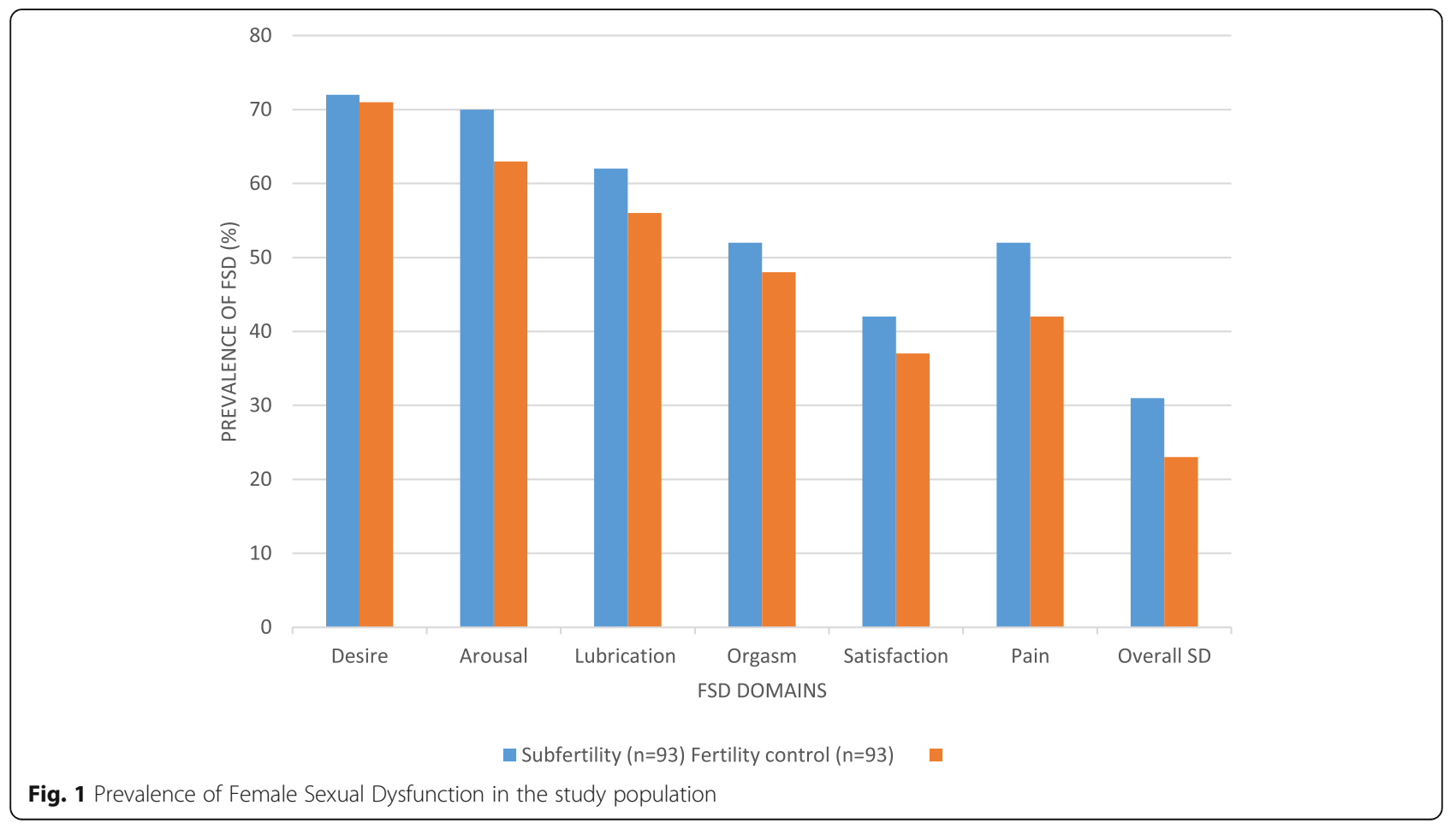


Table 3 Association of variables to female sexual dysfunction ( $f s d)$ in the subfertility group $(n=93)$

\begin{tabular}{|c|c|c|c|c|}
\hline Variable & Categories & FSD Prevalence (\%) & OR $(95 \% \mathrm{Cl})$ & $P$-value ${ }^{b}$ \\
\hline \multirow[t]{2}{*}{ Age (Years) } & $<35$ & 36.4 & 1 & 0.197 \\
\hline & $\geq 35$ & 23.7 & $0.54(0.21-1.39)$ & \\
\hline \multirow[t]{2}{*}{ Partner age (Years) } & $<40$ & 35.6 & 1 & 0.229 \\
\hline & $\geq 40$ & 23.5 & $0.56(0.21-1.47)$ & \\
\hline \multirow[t]{2}{*}{ BMI $\left(\mathrm{Kg} / \mathrm{m}^{2}\right)$} & Not obese & 30.7 & 1 & 0.827 \\
\hline & Obese & 33.3 & $1.13(0.38-3.40)$ & \\
\hline \multirow[t]{2}{*}{ Marital status } & Not married & 50 & 1 & 0.408 \\
\hline & Married & 30.3 & $0.44(0.06-3.32)$ & \\
\hline \multirow[t]{2}{*}{ Duration of marriage (years) } & $\leq 3$ & 28 & 1 & 0.799 \\
\hline & $>3$ & 30.8 & $1.14(0.41-3.19)$ & \\
\hline \multirow[t]{2}{*}{ Previous live birth } & None & 33.3 & 1 & 0.548 \\
\hline & Yes & 27.3 & $0.75(0.29-1.92)$ & \\
\hline \multirow[t]{2}{*}{ Previous miscarriage } & None & 34.5 & 1 & 0.379 \\
\hline & Yes & 25.7 & $0.66(0.26-1.68)$ & \\
\hline \multirow[t]{2}{*}{ Education level } & No college & 70 & 1 & 0.005 \\
\hline & College & 26.5 & $0.15(0.34-0.70)$ & \\
\hline \multirow[t]{2}{*}{ Frequency of coitus/ month } & $\leq 10$ & 32.6 & 1 & 0.791 \\
\hline & $>10$ & 30 & $0.88(0.37-2.15)$ & \\
\hline \multirow[t]{2}{*}{ Alcohol use } & None & 37.1 & 1 & 0.140 \\
\hline & Yes & 21.4 & $0.46(0.16-1.33)$ & \\
\hline
\end{tabular}

${ }^{\mathrm{b}}$ Chi square test

Table 4 Association of variables to female sexual dysfunction ( $f s d)$ in the fertility control group $(n=93)$

\begin{tabular}{|c|c|c|c|c|}
\hline Variable & Categories & FSD Prevalence (\%) & OR $(95 \% \mathrm{Cl})$ & $P$-value \\
\hline \multirow[t]{2}{*}{ Age (Years) } & $<35$ & 24.3 & 1 & 0.495 \\
\hline & $\geq 35$ & 17.4 & $0.66(0.19-2.22)$ & \\
\hline \multirow[t]{2}{*}{ Partner age (Years) } & $<40$ & 25.4 & 1 & 0.334 \\
\hline & $\geq 40$ & 15 & $0.52(0.13-2.01)$ & \\
\hline \multirow[t]{2}{*}{ BMI $\left(\mathrm{Kg} / \mathrm{m}^{2}\right)$} & Not obese & 22.7 & 1 & 0.967 \\
\hline & Obese & 22.2 & $0.97(0.28-3.38)$ & \\
\hline \multirow[t]{2}{*}{ Marital status } & Not Married & 23.2 & 1 & 0.905 \\
\hline & Married & 22.2 & $0.94(0.33-2.65)$ & \\
\hline \multirow[t]{2}{*}{ Previous live birth } & None & 21.7 & 1 & 0.777 \\
\hline & Yes & 24.2 & $0.86(0.31-2.38)$ & \\
\hline \multirow[t]{2}{*}{ Previous miscarriage } & None & 25.4 & 1 & 0.343 \\
\hline & Yes & 16 & $0.56(0.17-1.89)$ & \\
\hline \multirow[t]{2}{*}{ Education level } & No college & 25 & 1 & 0.865 \\
\hline & College & 22.4 & $0.86(0.16-4.68)$ & \\
\hline \multirow[t]{2}{*}{ Frequency of coitus/ month } & $\leq 10$ & 21.4 & 1 & 0.825 \\
\hline & $>10$ & 23.4 & $1.12(0.41-3.06)$ & \\
\hline \multirow[t]{2}{*}{ Alcohol use } & None & 26.9 & 1 & 0.116 \\
\hline & Yes & 13.2 & $0.41(0.13-1.29)$ & \\
\hline \multirow[t]{2}{*}{ Contraceptive use } & Non hormonal & 33.3 & 1 & 0.006 \\
\hline & Hormonal & 29.2 & $4(1.38-11.62)$ & \\
\hline
\end{tabular}


Table 5 Logistic regression analysis of the odds ratio of sexual dysfunction of each risk factor adjusted for other variables in the model

\begin{tabular}{lll}
\hline Risk factor & Adjusted OR (95\%) & $P$-value \\
\hline Subfertility & $1.87(0.92-3.80)$ & 0.085 \\
Age & $0.41(0.18-0.91)$ & $\mathbf{0 . 0 2 8}$ \\
Alcohol use & $0.40(0.18-0.89)$ & $\mathbf{0 . 0 2 4}$ \\
Education level & $0.35(0.12-1.03)$ & 0.058 \\
\hline
\end{tabular}

and interpersonal relationships. However, its burden has not been adequately assessed especially in sub-Saharan Africa. This study demonstrated that $26.9 \%$ of the study participants had sexual dysfunction. These findings are comparable to other studies showing a sexual dysfunction prevalence of $26-28 \%$ among reproductive age women [18, 25].

The prevalence reported in the present study is lower than that reported in other population based studies $[4,7,19-21]$. These studies however included menopausal women and had a lower number of women attaining above college level education. Our study population included only reproductive age women and had higher education attainment $(90.3 \%$ had college level education). Advancing age is associated with greater sexual dysfunction especially after menopause [21]. On the other hand, higher education has been shown in other studies to be protective of sexual dysfunction [2, 19]. For instance, Safarinejad (2006) showed a prevalence rate of sexual dysfunction among Iranian women of $31.5 \%$. The study participants however included menopausal women (range 20-60 years) with only $38.8 \%$ having above high school education. In Egypt, Ibrahim et al. (2013) found a 52.8\% prevalence of sexual dysfunction. However, majority (51.3\%) were post-menopausal and $71 \%$ had undergone female genital mutilation (FGM) hence the higher prevalence as advanced age adversely affects sexual function and possibly female FGM especially if type II or III. Moreover, only $15.2 \%$ had college education.

The primary aim of our study was to compare the prevalence of sexual dysfunction between patients on follow up for subfertility and those seeking fertility control services. We found a prevalence of sexual dysfunction of 31.2 and $22.6 \%$ in the subfertility and fertility control groups respectively. Despite the apparent difference in the prevalence of sexual dysfunction in the two groups, analysis of data from the study demonstrated no statistically significant difference in the prevalence of sexual dysfunction between subfertility and fertility control subjects (adjusted odds ratio 1.87, CI 0.92-3.80, $p=$ 0.085). The subfertile group had lower mean total FSFI and domain scores though only the satisfaction score was statistically significant from the fertility control group. The decreased satisfaction is possibly due to low self-esteem and poor body-image as a result of or as a cause of the subfertility. Moreover, the psycho-social pressures to conceive stemming from "sex-on-demand" might result in loss of couple intimacy [9]. The absence of significant difference in sexual function could be due to fact that the study was conducted in a tertiary private hospital whose clientele are more likely to be of a higher socioeconomic status with higher education attainment making them more aware of their own bodies and hence sexual performance.

Studies on the association between subfertility and female sexual dysfunction have reported conflicting results. Iris et al. (2013) and Furukawa et al. (2012) found no significant difference in the prevalence of sexual dysfunction between subfertile and fertile women [22, 23], similar to the present study findings. Iris et al. (2013) in their study ( $n=809$ ) with 174 being subfertile, demonstrated a significantly greater prevalence of sexual dysfunction with increasing duration of subfertility though there was no significant difference in sexual dysfunction between the subfertile and fertile groups [22]. However, this study by was not powered to detect the difference in sexual dysfunction between subfertile and fertile groups and excluded women with secondary subfertility, a known risk factor for sexual dysfunction [13]. The present study found no significant association of sexual dysfunction with subfertility duration. On the other hand, Furukawa et al. (2012) in a study comparing the rate of dyspareunia and sexual dysfunction among women seeking fertility services found no significant association between subfertility and sexual function (adjusted odds ratio 1.44, CI 0.77-2.69, $p=0.25$ ). Moreover, just like the present study findings, the subfertile subjects were more likely to be married [23].

The findings of lower total and individual domain FSFI scores among subfertility patients have also been reported in other studies $[9,24,26]$. To determine the effect of subfertility on sexual function, Ashraf et al. studied 384 Iranian women divided in two groups (fertile and subfertile). Using the FSFI, the mean sexual function scores were significantly lower in the subfertile group [24]. However, only $47.4 \%$ of their subfertility subjects had college level education unlike our subjects (90.3\%). Similarly, Tanha et al., (2014) demonstrated a significantly lower individual domain and total FSFI scores in the subfertile subjects in comparison with the controls [24] while Mirblouk et al., (2016) found a significantly greater occurrence of sexual dysfunction among the subfertile subjects [26]. Milheiser et al., compared 119 subfertile and 99 fertile women and found a 40\% prevalence of sexual dysfunction in the subfertile group compared to $25 \%$ in the fertile group with the subfertile group having significantly lower mean total, desire and arousal scores. Interestingly, they found a significantly lower 
frequency of coitus among the subfertile group [9]. This is unusual for subfertile subjects who are expected to have more frequent intercourse in order to increase their fecundability. In the present study, the frequency of coitus was not significantly associated with sexual dysfunction.

In the current study, the most common alterations in both the subfertile and fertility control groups were lack of desire and arousal. These finding are similar to those by Mirblouk et al. (2016) that demonstrated a greater occurrence of desire, arousal and orgasmic dysfunctions [27]. A high correlation between sexual desire and arousal make the desire and arousal disorders to be among the commonest complaints in clinical practice. Aggarwal et al. (2013) similarly found arousal dysfunction to be the most prevalent among the subfertile women (70\%) while desire and orgasmic dysfunctions were the most prevalent in the fertility group each at $40 \%$ [10]. Moreover, just like the present study, the prevalence arousal, lubrication and pain dysfunctions was higher in the subfertility group. The findings differed with the present study by demonstrating a lower prevalence of desire, orgasmic and satisfaction dysfunctions in the subfertility group. Khademi et al. (2008) demonstrated an $80 \%$ prevalence of arousal dysfunction and a $22 \%$ orgasmic dysfunction among subfertility women [28].

Secondarily, the present study sought to assess the difference in sexual function between subjects with primary and those with secondary subfertility. There was no statistically significant difference in sexual dysfunction between subjects with primary and secondary subfertility. These findings are similar to those by Kabil et al. (2015) and Keskin et al. (2011). Kabil and colleagues examined the effects of subfertility aetiology and depression on the female sexual function. They compared sexual function among 83 and 59 women with primary and secondary subfertility respectively and did not find any difference in FSD between the two groups [12]. Similarly, an Iranian study by Tanha et al. (2014) which included 191 women with primary subfertility and 129 women with secondary subfertility demonstrated no statistically significant difference in sexual dysfunction between women with primary and secondary subfertility [26]. However, a Turkish study by Keskin et al. (2011), which included 122 and 51 women with primary and secondary subfertility respectively found a significantly lower individual and total FSFI scores in the secondary subfertile group [13].

We further sought to determine the association between the various sociodemographic variables and sexual dysfunction. Among the various socio-demographic variables, only education level and use of hormonal contraception were significantly associated with sexual dysfunction in the subfertility group and fertility control groups respectively. In the subfertility group, attainment of college level education appeared to be protective against sexual dysfunction. Higher education level has been shown to be protective of sexual dysfunction in other studies $[19,20]$. This is possibly due to better health seeking behaviours associated with higher education. Use of hormonal contraception in the fertility control group was associated with a greater occurrence of sexual dysfunction. Previous similar studies yielded conflicting results. Fataneh et al. (2013) evaluated 608 married Iranian women aged 15-49 years (case group $=306$ and control $=302$ ). The case group was those on contraception. The study showed a significant impairment in sexual function in the case group though only $26.8 \%$ were on hormonal contraception (pills). Moreover, those using barrier methods and vasectomy had a better sexual functioning [29]. In contrast, studies by Safarinejad (2006) and Li et al. (2004) failed to show any significant impairment of sexual function among women on various contraceptive methods $[16,20]$. A systematic review by Pastor et al. (2013) that evaluated 36 studies (1978-2011; 13, 673 women) also found no significant impairment in sexual desire in women on combined oral contraceptive pill use [14]. The greater occurrence of sexual dysfunction in the present study would be attributed to the smaller study numbers and the fact that the study wasn't powered to specifically evaluate for the association between contraceptive use and FSD.

Given that there was no significant difference in FSD in the subfertile and fertility control groups, the two groups were assessed together for factors with possible association with FSD. The variables found to be significantly associated to sexual dysfunction were maternal age and alcohol use. Maternal age above 35 years of age appeared to be protective (adjusted odds ratios 0.41, CI $0.18-0.91, p=0.028$ ). This is possibly due to the population bias and a possible better socioeconomic status of women above the age of 35 years. Moreover, they possibly have a better understanding of their own sexuality than the younger women. Alcohol use also appeared to be protective (adjusted odds ratio 0.40, CI 0.18-0.89, $p=0.024)$. Alcohol use possibly makes women more expressive of their sexual feelings hence less occurrence of sexual dysfunction.

Some of the limitations of the present study include that it was conducted in a tertiary private hospital whose clientele are generally of a higher education level and socioeconomic status and therefore, the results may not be generalizable to the general population. Secondly, given the sensitive nature of the subject matter, the study subjects might have been emotionally swayed in their responses to the questions. We also had little information regarding the women's partners which may have affected their sexual function. 


\section{Conclusions and recommendations}

In conclusion, the present study demonstrated no association between the fertility status and the prevalence female sexual dysfunction. Subfertility type was not associated with sexual dysfunction. Education level and use of hormonal contraception were associated with sexual dysfunction in the subfertility and fertility control groups respectively while alcohol use and higher maternal age appeared to be protective against female sexual dysfunction. Given the limitations of the present study, we recommend a large multi-centre study in our setting to further evaluate the association between subfertility and sexual dysfunction.

\section{Abbreviations}

BMI: Body Mass Index; Cl: Confidence Interval; DSM-IV: Diagnostic and Statistical Manual of Mental Disorders, 4th edition.; FSD: Female Sexual Dysfunction; FSFI: Female Sexual Function Index; FSFI-Q: Female Sexual Index Questionnaire; SD: Standard Deviation; OR: Odds Ratio

\section{Acknowledgements}

The management, staff, faculty members, and my colleagues for their invaluable input and for being a great source of support to me during this study.

\section{Authors' contributions}

FMO was involved in the development of the research question, collection of data, analysis of the data, drafting of the manuscript and final approval of the manuscript. AM was involved in the analysis of the data, drafting of the manuscript and final approval of the manuscript. VML was involved in the development of the research question, analysis of the data, drafting of the manuscript and final approval of the manuscript. AMM was involved in the development of the research question, analysis of the data, drafting of the manuscript and final approval of the manuscript.

\section{Funding}

This study was funded by a research grant offered for postgraduate trainees at the Aga Khan.

University Hospital. The funding had no role in the collection, analysis and interpretation or result findings.

\section{Availability of data and materials}

The datasets used and analyzed during the current study are available from the corresponding author on reasonable request.

\section{Ethics approval and consent to participate}

Ethics approval was obtained from the Research and Ethics committee at the Aga khan University Hospital.

Participants were recruited after obtaining written informed consent as per study protocol.

Patients had the right to refuse or withdraw from the study at any point and this did not impact on the quality of care received subsequently.

\section{Consent for publication}

No patients' individual data was used in the present study and hence no consent was needed for publication.

\section{Competing interests}

The authors declare that they have no competing interests

Received: 21 March 2019 Accepted: 8 November 2019

Published online: 23 November 2019

\section{References}

1. Chedraui P, Perez-Lopez FR, Mezones-Holguin E, San Miguel G, Avila C. Assessing predictors of sexual function in mid-aged sexually active women. Maturitas. 2011;68(4):387-90.
2. Blumel JE, Chedraui P, Baron G, Belzares E, Bencosme A, Calle A, et al. Sexual dysfunction in middle-aged women: a multicenter Latin American study using the Female Sexual Function Index. Menopause. 2009;16(6):1139-48.

3. Ahmed MR, Madny EH, Sayed Ahmed WA. Prevalence of female sexual dysfunction during pregnancy among Egyptian women. J Obstet Gynaecol Res. 2014:40(4):1023-9.

4. Oksuz E, Malhan S. Prevalence and risk factors for female sexual dysfunction in Turkish women. J Urol. 2006;175(2):654-8 discussion 8.

5. Raina R, Pahlajani G, Khan S, Gupta S, Agarwal A, Zippe CD. Female sexual dysfunction: classification, pathophysiology, and management. Fertil Steril. 2007;88(5):1273-84.

6. Basson R, Berman J, Burnett A, Derogatis L, Ferguson D, Fourcroy J, et al. Report of the international consensus development conference on female sexual dysfunction: definitions and classifications. J Urol. 2000;163(3):888-93.

7. Laumann EO, Paik A, Rosen RC. Sexual dysfunction in the United States: prevalence and predictors. Jama. 1999;281(6):537-44.

8. Lightner DJ. Female sexual dysfunction. Mayo Clin Proc. 2002;77(7):698-702

9. Millheiser LS, Helmer AE, Quintero RB, Westphal LM, Milki AA, Lathi RB. Is infertility a risk factor for female sexual dysfunction? A case-control study. Fertil Steril. 2010;94(6):2022-5.

10. Aggarwal RS, Mishra W, Jasani AF. Incidence and prevalence of sexual dysfunction in infertile females. Middle East Fertil Soc J. 2013;18(3):187-90.

11. Wischmann TH. Sexual disorders in infertile couples. J Sex Med. 2010;7(5): 1868-76.

12. Kucur Suna K, llay G, Aysenur A, Kerem Han G, Eda Ulku U, Pasa U, et al. Effects of infertility etiology and depression on female sexual function. J Sex Marital ther. 2016;42(1):27-35.

13. Keskin U, Coksuer H, Gungor S, Ercan CM, Karasahin KE, Baser I. Differences in prevalence of sexual dysfunction between primary and secondary infertile women. Fertil Steril. 2011:96(5):1213-7.

14. Pastor Z, Holla K, Chmel R. The influence of combined oral contraceptives on female sexual desire: a systematic review. Eur J Contracept Reprod Health Care. 2013;18(1):27-43.

15. Schaffir JA, Isley MM, Woodward M. Oral contraceptives vs injectable progestin in their effect on sexual behavior. Am J Obstet Gynecol. 2010; 203(6):545.e1-5.

16. Li RH, Lo SS, Teh DK, Tong NC, Tsui MH, Cheung KB, et al. Impact of common contraceptive methods on quality of life and sexual function in Hong Kong Chinese women. Contraception. 2004;70(6):474-82.

17. Rosen R, Brown C, Heiman J, Leiblum S, Meston C, Shabsigh R, et al. The female sexual function index (FSFI): a multidimensional self-report instrument for the assessment of female sexual function. J Sex Marital ther. 2000;26(2):191-208.

18. Wiegel M, Meston C, Rosen R. The female sexual function index (FSFI): crossvalidation and development of clinical cutoff scores. J Sex Marital ther. 2005; 31(1):1-20.

19. Abdo $\mathrm{CH}$, Oliveira WM Jr, Moreira ED Jr, Fittipaldi JA. Prevalence of sexual dysfunctions and correlated conditions in a sample of Brazilian women-results of the Brazilian study on sexual behavior (BSSB). Int J Impot Res. 2004;16(2):160-6.

20. Safarinejad MR. Female sexual dysfunction in a population-based study in Iran: prevalence and associated risk factors. Int J Impot Res. 2006; 18(4):382-95.

21. Aslan E, Beji NK, Gungor I, Kadioglu A, Dikencik BK. Prevalence and risk factors for low sexual function in women: a study of 1,009 women in an outpatient clinic of a university hospital in Istanbul. J Sex Med. 2008;5(9): 2044-52.

22. Iris A, Aydogan Kirmizi D, Taner CE. Effects of infertility and infertility duration on female sexual functions. Arch Gynecol Obstet. 2013;287(4):809-12.

23. Furukawa AP, Patton PE, Amato P, Li H, Leclair CM. Dyspareunia and sexual dysfunction in women seeking fertility treatment. Fertil Steril. 2012;98(6): 1544-8.e2.

24. Ashraf DM, Ali D, Azadeh DM. Effect of Infertility on Sexual Function: A Cross-Sectional Study. Journal of clinical and diagnostic research. JCDR. 2015;9(5):Qc01-3.

25. Ramezani Tehrani F, Farahmand M, Simbar M, Malek AH. Factors associated with sexual dysfunction; a population based study in Iranian reproductive age women. Arch Iran Med. 2014;17(10):679-84.

26. Davari Tanha F, Mohseni M, Ghajarzadeh M. Sexual function in women with primary and secondary infertility in comparison with controls. Int J Impot Res. 2014;26(4):132-4. 
27. Mirblouk F, Asgharnia DM, Solimani R, Fakor F, Salamat F, Mansoori S. Comparison of sexual dysfunction in women with infertility and without infertility referred to Al-Zahra Hospital in 2013-2014. Int J Reprod Biomed (Yazd). 2016;14(2):117-24.

28. Khademi A, Alleyassin A, Amini M, Ghaemi M. Evaluation of sexual dysfunction prevalence in infertile couples. J Sex Med. 2008;5(6):1402-10

29. Fataneh $G$, Marjan $M H$, Nasrin $R$, Taraneh $T$. Sexual function in Iranian women using different methods of contraception. J Clin Nurs. 2013; 22(21-22):3016-23.

30. Meston CM, Buss DM. Why humans have sex. Arch Sex Behav. 2007;36(4): 477-507.

\section{Publisher's Note}

Springer Nature remains neutral with regard to jurisdictional claims in published maps and institutional affiliations.

Ready to submit your research? Choose BMC and benefit from:

- fast, convenient online submission

- thorough peer review by experienced researchers in your field

- rapid publication on acceptance

- support for research data, including large and complex data types

- gold Open Access which fosters wider collaboration and increased citations

- maximum visibility for your research: over $100 \mathrm{M}$ website views per year

At BMC, research is always in progress.

Learn more biomedcentral.com/submissions 